range of vertebrate types. By original methods of great beauty and refinement, he has provided some of the most important available evidence concerning this excretory function. During the War of 1914-18, he crossed the Atlantic at short notice, in 1917, to collaborate with Dr. (now Sir Henry) Dale and the late Dr. P. P. Laidlaw in researches on traumatic shock, and joined with these workers in publications on the action of histamine and on related problems. Last year Prof. Richards became the first chairman of the newly appointed Committee on Medical Research of the United States, under the Office of Scientific Research and Development. No man is more fitted than he to promote the friendly collaboration in medical researches of the whole Englishspeaking world, both now and after the War.

\section{Prof. L. Ruzicka}

THE arrival, all too infrequently, of neatly bluebound reprints continues to remind us of the energetic prosecution of the steroid hormone field by the school of chemistry in Zurich. Two and a half years ago we had the pleasure of referring to Prof. L. Ruzicka's election as a Nobel Laureate for the year 1939 -an honour which he shared with Prof. Butenandt (NAtuRE, 144, 858; 1939). A brief account was given there of the work for which the award was made. To-day we welcome Prof. Ruzicka's election to the foreign membership of the Royal Society. His work forms the basis of the advances leading to the whole subject of the steroid hormones. It will be remembered that his great contribution consisted in his recognition of the importance of the residual part of the sterol molecule which remained after removal of the side chain. With characteristic insight Ruzicka realized that which the Göttingen workers had failed to see; namely, that the cyclopentenophenanthrene nucleus left after the above operations presented a jumping-off ground for further important investigations. There followed that brilliant series of researches leading to the male hormone progesterone, corticosterone and so on. It will be recalled that his early publications resulted in one of the most bitter polemics in science the century has known. Since the Nobel award, Ruzicka's main work has been the extension and amplification of the various substances that can be made from sterol disintegration. Numerous papers have appeared from his laboratory, many of which have recently arrived in Great Britain.

\section{Prof. N. I. Vavilov}

Prof. Nicholas Ivanovitch Vavilov's most important work has been on the origin of cultivated plants. His method was to make well-planned expeditions to those regions where cultivated plants grow wild, and he obtained strong evidence that countries where a large number of varieties of a particular plant occurs are the actual areas of origin. Conditions favouring genetical instability would, he argued, probably lead to the formation of a new species. It is remarkable how narrow is the belt along which cultivated plants arose. Mexico and Central America are the source for the Now World, and Abyssinia, Persia, Afghanistan and an extension of this zone across Northern India into China, furnished the Old World with its crops. Prof. Vavilov has discussed the close relations between the origins of cultivated plants, of animals, and of ancient eivilizations. He is, however, no mere collector. His material was taken back to Russia and there grown and studied in detail. He has become the leading taxonomist of cultivated plants, and he has also done valuable plant-breeding work and made important contributions to genetical science. He is well known to British and American scientific workers, having studied at the John Innes Horticultural Institution and visited various research centres, such as Rothamsted arid others in Great Britain and also in the United States ; and his complete command of the English language and lively humour and social gifts have always made him a welcome guest. His election to this new distinction will cause much satisfaction to many in Great Britain.

\section{Prof. I. M. Vinogradov}

Prof. I. M. Vinogradov is a member of the Academy of Sciences of the U.S.S.R. and he is universally acknowledged as the world's foremost investigator in the analytic theory of numbers. For years past he has produced a succession of discoveries, some of which can be described in no other way than as epoch-making. Many others are of vital importance and have also made mathematical history. They are already part of the fundamental equipment which must be acquired by anyone who studies numbertheory. Many problems, in which there seemed little or no hope of any progress, yielded to his methods, which combine a wonderful imagination, great power and comparative simplicity ; their possibilities have not begun to be exhausted. His most famous work is associated with Goldbach's theorem that every even number is the sum of two prime numbers. This theorem has been known for about two hundred years, but has never been proved. Vinogradov proved that every sufficiently large odd number is the sum of three primes. This is a result of a type, so dificult to prove, that it was considered a notable achievement when progress was made about twenty years ago by Hardy and Littlewood; even though their proof depended upon making assumptions of a type as difficult to prove as the famous Riemann hypothesis. The importance of Vinogradov's results may be gauged from the pecuniary recognition given to him by the Soviet Government. Well known also is his new solution of Waring's problem, leading to results far more precise than those first discovered by Hardy and Littlewood.

\section{Two Eminent German Men of Science}

IN the first week of July occur the bicentenary of the birth of the German physicist and writer, Georg Christoph Lichtenberg, of Göttingen, and the centenary of the birth of the German chemist, Albert Ladenburg, both of whom were well known in British. scientific circles. Lichtenberg was born on July 1, 1742, at Oberramstadt near Darmstadt, and was the youngest child in a family of eighteen. As a youth he became a hunchback and was thus confined more or less to sedentary occupations. Entering the University of Göttingen at the age of twenty-one, he afterwards worked at the Observatory and when twenty-eight was made professor of mathematics. His first visit to England was made in 1770 ; his second in 1774. He was then made a fellow of the Royal Society. Returning to Göttingen in 1775, he became tutor to the Dukes of Clarence, Cumberland and Cambridge, and two years later was chosen to succeed Erxleben in the chair of physics, a post he held until his death on February 24, 1799. As a physicist he is remembered for his observations on 